\title{
A EJA EM TEMPOS DE PANDEMIA DE COVID-19: REFLEXÕES SOBRE OS DIREITOS E POLÍTICAS EDUCACIONAIS NA AMAZÔNIA BRAGANTINA
}

\author{
Alessandra Sampaio Cunha ${ }^{1}$ \\ Joana d'Arc Vasconcelos Neves ${ }^{2}$ \\ Nívia Maria Vieira Costa ${ }^{3}$
}

\begin{abstract}
RESUMO
Este trabalho teve como temática a discussão do direito e das políticas educacionais, dando ênfase na Educação de Jovens e Adultos- EJA em tempos de pandemia na Amazônia bragantina. O objetivo da investigação foi analisar o alcance do direito a educação de jovens e adultos diante das políticas educacionais brasileiras e em tempos de pandemia na Amazônia bragantina. A metodologia utilizada preocupou-se em abranger uma abordagem qualitativa, por meio pesquisa documental articulando informações de pareceres e legislações / estatísticas da EJA do município de Bragança-PA, no sentido de cruzar os dados e informações num movimento circular (SAMPIERI, CALLADO E LUCIO, 2013) e qualificar o corpus de análise. Os resultados levantados mostram antigas e novas questões sobre uma Educação de Jovens e Adultos pautadas em políticas compensatórias de diminuições de tempos e conteúdos, de fechamento de turmas, de diminuição do número de matrículas, fechamento dos programas específicos para a EJA, agravado ainda mais em tempos de pandemia em virtude do silenciamento diante garantia do acesso as instituições de ensino ao público desta modalidade de ensino.
\end{abstract}

Palavras-chave: Direito Fundamental. Educação de Jovens e Adultos. Políticas Públicas. Pandemia Covid-19.

\section{EJA IN COVID 19 PANDEMIC TIMES: \\ THINKING OVER EDUCATIONAL RIGHTS AND POLICIES IN BRAGANÇA- AMAZON}

\begin{abstract}
This work had as its theme the discussion of educational law and policies, emphasizing Youth and Adult Education - EJA in times of pandemic in the bragantina Amazon. The objective of the investigation was to analyze the scope of the right to education for young people and adults in the face of Brazilian educational policies and in times of pandemic in the bragantina Amazon. The methodology used was concerned with encompassing a qualitative approach, through documentary research articulating information from EJA opinions and legislation / statistics in the municipality of Bragança-PA, in order to cross the data and information in a circular movement (SAMPIERI, CALLADO \& LUCIO, 2013) and qualify the analysis corpus. The surveyed results show old and new questions about Youth and Adult Education based on compensatory policies for decreasing time and content, closing classes, reducing enrollment, closing specific programs for EJA, further aggravated in pandemic times due to silencing before guaranteeing access to educational institutions to the public of this teaching modality.
\end{abstract}

Keywords: Fundamental Law. Youth and Adult Education. Public policy. Covid-19 Pandemic.

\footnotetext{
${ }^{1}$ Doutora em Ciências da Educação (Universidades de Trás-os-Montes e Alto Douro/UTAD - Portugal). Técnica em Assuntos Educacionais do Instituto Federal de Educação, Ciências e Tecnologia do Pará -IFPA/Campus Bragança. E- mail: alessandra.sampaio@ifpa.edu.br.

2 Pós-doutora em Sociedade, Ambiente e Qualidade de Vida (UFOPA). Doutora em Educação (UFPA). Professora da Universidade Federal do Pará- UFPA/ Campus Bragança. E-mail: jdneves@ufpa.br.

${ }^{3}$ Pós-doutora em Educação de Adultos (Universidade de Coimbra - Portugal). Doutora em Educação (UFC). Professora do Instituto Federal de Educação, Ciências e Tecnologia do Pará -IFPA/Campus Bragança. E-mail: nivia.costa@ifpa.edu.br.
} 
Data de submissão: 30.09 .2020

Data de aprovação: 06.12.2020

\section{INTRODUÇÃOO}

O presente trabalho teve como foco de estudo o silenciamento e negação dos direitos à Educação de Jovens e Adultos - EJA, em especial em tempos da Pandemia do Covid-19. O interesse por esta temática é resultado de inquietações que permeiam enquanto pesquisadoras que têm como campo de estudo a modalidade da EJA.

Historicamente o movimento em defesa ao direito de educação aos jovens e adultos que foram excluídos da educação escolarizada, tem se contrapondo às políticas públicas e é com muita frequência ainda visto como educação compensatória, de forma pontual e reproduções de modelos escolares para as crianças.

A educação no contexto da pandemia global do novo coronavírus (COVID-19) marcado por incertezas, teve um grande impacto e provocou muitas reflexões, mudanças rápidas e exigiu repensar novas formas de ensinar e aprender a partir da suspensão das aulas presenciais e do isolamento social. Tal cenário, segundo os dados da Organização das Nações Unidas para a Educação, a Ciência e a Cultura - UNESCO no mês de abril de 2020, foram suspensas às aulas em 194 países, atingindo cerca de 1,6 bilhão de crianças e jovens no mundo inteiro (UNESCO, 2020).

O reflexo da educação no mundo, agravou ainda mais a realidade da educação brasileira que além de desmascarar a situação precária ficou mais sucateado o ensino das escolas públicas, principalmente, em determinadas regiões e populações como a Amazônica. No contexto amazônico e diante da situação atual pandêmica, a EJA enfrenta grandes desafios por se tratar de sujeitos com processos de exclusões históricas e com diversidades muito específicas.

Os diálogos sobre os movimentos em defesa da necessidade de criar e de dar continuidade às políticas públicas para a EJA que tenham por princípios, o respeito às diversidades, às realidades e às especificidades dos alunos, assegurando não apenas o acesso, mas também, a permanência dos mesmos no âmbito escolar, assim como a compreensão da EJA como princípio fundamental do ser humano, trouxeram também novas reflexões entre o que diz a legislação e o que de fato conseguem implementar e materializar, o que nos levou a questionar: que estratégias ou políticas públicas são construídas para a garantia da EJA como direito humano em tempos de pandemia? Essas estratégias conseguem materializar um projeto de EJA que potencializa a cidadania dos jovens e adultos que a acessam?

Tais questionamentos nos impulsionaram à organização da pesquisa; assim traçamos como objetivo geral: analisar os direitos e as políticas para Educação de Jovens e Adultos em um município da Amazônia bragantina, frente ao contexto da pandemia de Covid-19; E para tanto se delineou: a) Estabelecer a relação teórica entre as políticas da educação de jovens e adultos como campo de disputas e lutas de garantia do direito; b) Analisar as formas de organização educacional da EJA em um município da Amazônia bragantina; c) Analisar os possíveis impactos no processo de escolarização de Jovens e Adultos na Amazônia bragantina em tempos de pandemia de Covid-19; d) Propor estratégias que visam a garantia desse direito em contexto de pandemia de Covid-19;

Com o objetivo de interpretar o fenômeno em questão, ou seja, a garantia do direito à Educação de Jovens e Adultos em tempos de pandemia, apoiamos nossos estudos na abordagem qualitativa (LÜDKE E ANDRÉ, 2013). Para tal, usamos a pesquisa documental.

A pesquisa documental nos permitiu investigar de forma indireta, por meio do estudo dos documentos produzidos a respeito da EJA, dentre os quais destacamos: a) Os documentos internacionais (Declaração dos direitos humanos e as Cartas das CONFINTEAS); b) Os 
documentos nacionais (Constituição de 88, LDB 96, Diretrizes Curriculares da EJA, Documentos orientadores dos Fóruns de EJA); c) Os documentos locais (Plano Municipal de Educação, Diretrizes Operacionais da EJA, Conselho Municipal de Educação); as estatísticas da EJA no município e nas plataformas de informação IBGE, DEEPASK, INEP.

A escolha do Município de Bragança, na Amazônia bragantina, configura-se em virtude do município ter 407 anos de existência, com uma rica diversidade ambiental e sociocultural, contexto de diferentes formas de produção de existências: agricultores, pescadores, coletores, ribeirinhos e quilombolas. Entretanto, $49,8 \%$ da população bragantina possui uma renda média de até meio salário mínimo e ocupa a posição 1.938 na escala de renda entre 5.570 municípios brasileiros. Aliada ainda, ao fato de apresentar um quadro de 11.690 pessoas acima de 15 anos analfabetas, ou seja, 15,33\% do total da população do município, necessitam que seus direitos à escolarização sejam garantidos pelo poder público municipal (DEEPASK, 2018).

Os dados coletados foram organizados num movimento circulatório onde se cruzaram as informações das diferentes fontes documentais, visando qualificar o corpus de análise (SAMPIERI, CALLADO E LUCIO, 2013).

Os resultados desse movimento de cruzar informações e interpretar os sentidos e significados, encontram-se organizados nos três tópicos desse trabalho: o primeiro discorre sobre as políticas educacionais brasileiras e a constituição da Educação de Jovens e Adultos como modalidade para assegurar o direito dessa população a educação; o segundo apresentamos a EJA na Amazônia bragantina, suas políticas, concepções e as implicações no campo do direito à educação em tempos de pandemia do Covid-19; e o terceiro traz reflexões sobre os possíveis caminhos e estratégias de inclusão da EJA ao universo educacional em meio à pandemia ainda em curso.

\section{EDUCAÇÃO DE JOVENS E ADULTOS COMO CAMPO DE DISPUTAS POR DIREITOS}

A Educação de Jovens e Adultos, como modalidade de ensino no Brasil, tem se configurado em um campo de disputas acerca do direito à educação de jovens e adultos que historicamente sofreram e sofrem diferentes formas de exclusão social. A garantia do direito à educação, não se trata apenas do direito à escola, trata-se do direito à própria vida, na medida em que o acesso a ele potencializa afirmação da dignidade humana,

[...] o direito à educação enquanto direito humano fundamental assume papel relevante
para a afirmação da dignidade humana, pois sem a possibilidade de crescimento
intelectual, de desenvolvimento de suas aptidões cognitivas, o ser humano não poderá
desfrutar de outros direitos, uma vez que será excluído da sociedade letrada, tratado à
margem desse contexto, não sendo visto como igual em direitos e nem tratado com
dignidade. Daí o caráter de Direito Humano Fundamental atribuído à educação, tão
precioso e necessário quanto a própria vida, pois tal direito é a alavanca para a realização
de tantos outros. Sendo assim, a educação deve ser compreendida como um bem
fundamental da humanidade. (CARVALHO, BARBOSA, RODRIGUES, TEIXEIRA,
2010, p.3).

Neste sentido, versar sobre a Educação de Jovens e Adultos como um direito humano fundamental, implica compreender as políticas construídas em prol desse princípio de que estão marcadas por conflitos e contradições em torno das concepções da educação.

Ao longo de todo o século passado em nível internacional a Conferência Internacional de Educação de Adultos-CONFINTEAS, apresenta esse movimento de construções que destacam inicialmente a necessidade da especificidade, da alfabetização para cidadania; da educação para superação da carência cultural, a defesa da educação ao longo da vida, o reconhecimento do direito de aprender, como também, apresentam articulações à temáticas 
mais variadas: alfabetização de adultos, pós-alfabetização, educação rural, educação familiar, educação da mulher, educação em saúde e nutrição, educação cooperativa, educação vocacional, educação técnica, ou ainda, temáticas correlacionada ao desenvolvimento ecológico sustentável, da democracia, da justiça, da igualdade entre os sexos, do desenvolvimento socioeconômico e científico (NEVES, SILVA JÚNIOR E GONÇALVES, 2019).

No Brasil em diferentes momentos históricos, projetos de educação jovens e adultos pautados: a) nos setores populares, incentivam a organização e autonomia da classe trabalhadora, engajando-os num projeto de transformação social; b) na lógica da educação escolar supletiva; ou ainda c) na lógica mercadológica, fomentaram/fomentam tensões e disputas que delineiam as políticas públicas escolar.

A Constituição Federal de 1988, inaugura no cenário educacional Brasileiro o debate sobre a garantia obrigatória e gratuita da oferta de educação para todos que não tiveram acesso em idade própria, conforme artigo 208, inciso I, em que afirma,

O dever do estado com a educação será efetivado mediante a garantia de: I - educação básica obrigatória e gratuita dos quatro aos dezessete anos de idade, assegurada inclusive sua oferta gratuita para todos os que a ela não tiveram acesso na idade própria (BRASIL, 1988).

Ressalta-se que o reconhecimento desse direito permite, por sua vez, que a escolarização de jovens e adultos deixe de ser pensada como ensino suplência, voltada para instrução e, provoca mudanças que vão como descreve Soares (2002), muito além do que atualização vocabular que levam a reafirmação da EJA como uma modalidade de educação básica.

Contraditoriamente, autores como Neves, Silva Júnior e Gonçalves (2019) destacam que apesar da Lei de Diretrizes e Bases da Educação - LDB, n 9.394/96 trazer a concepção EJA como modalidade da educação básica, isso não significou a superação por completo da EJA como supletivo.

Entretanto, como analisam Di Pierro e Haddad (2015), a mobilização da sociedade civil no Brasil foi propulsora da conquista de direitos, como o reconhecimento dos jovens e adultos dentre os sujeitos do direito humano à educação, antes restrito às crianças e adolescentes. $\mathrm{O}$ que terminou por potencializar inúmeros marcos legais dentre os quais: o Parecer CNE/CEB n ${ }^{\circ} 11 / 2000$ que institui as Diretrizes Curriculares Nacionais para a Educação de Jovens e Adultos e a Resolução n ${ }^{\circ}$ 3/ 2010 que Institui Diretrizes Operacionais para a Educação de Jovens e Adultos.

O Parecer CNE/CEB n¹1/2000, que define a Educação de Jovens e Adultos como,

Uma dívida social não reparada para com os que não tiveram acesso e nem domínio da escrita e leitura como bens sociais, na escola ou fora dela, e tenham sido a força de trabalho empregada na constituição de riquezas e na elevação de obras públicas. Ser privado deste acesso é, de fato, a perda de um instrumento imprescindível para uma presença significativa na convivência social contemporânea (BRASIL, 2000, p. 5).

Neste documento a EJA reassume as funções reparadoras, equalizadoras e qualificadoras e, como destaca o próprio documento, "representa uma promessa de efetivar um caminho de desenvolvimento de todas as pessoas, de todas as idades" (BRASIL, 2000, p.10).

Já a Resolução nº 3 /2010 Institui Diretrizes Operacionais para a Educação de Jovens e Adultos nos aspectos relativos à duração dos cursos e idade mínima para ingresso nos cursos de EJA; idade mínima e certificação nos exames de EJA; e Educação de Jovens e Adultos desenvolvida por meio da Educação a Distância, a serem obrigatoriamente observadas pelos sistemas de ensino, na oferta e na estrutura dos cursos e exames de Ensino Fundamental e 
Ensino Médio que se desenvolvem em instituições próprias integrantes dos Sistemas de Ensino Federal, Estaduais, Municipais e do Distrito Federal (BRASIL, 2010).

Neste contexto, os fóruns de EJA defendem políticas para esta modalidade de ensino que objetivem uma escolarização básica de qualidade para que todos os sujeitos da EJA tenham uma boa qualidade de vida, o que para Machado (2009, p. 34) implica em "processo de convencimento das pessoas não escolarizadas de que faz sentido a luta pelo acesso ao conhecimento".

Entretanto, ressalta-se que nas contradições existentes em projetos educacionais que se encontram mergulhados no neoliberalismo e na busca em torno do direito à educação, os esforços por colocar a EJA na agenda dos governos não resultam em avanços significativos. Como analisa de Di Pierro (2010, p. 952),

\footnotetext{
No plano Nacional da Educação o tópico dedicado à EJA no Eixo VI, da CONAE, intitulado "Justiça Social, Educação e Trabalho: Inclusão, Diversidade e Igualdade", foi ampliado em mais de dez páginas, nas quais se distribui - sem qualquer hierarquia - um extenso rol de proposições de diferentes ordens, relativas às concepções pedagógicas, ao planejamento e às estratégias de políticas públicas, à ampliação da oferta e do financiamento, melhoria da infraestrutura, da formação inicial e continuada dos educadores e das condições de trabalho docente, consideração da diversidade dos educandos, fiscalização do setor privado, produção de estatísticas e pesquisas, supervisão e normas, organização escolar, currículos, materiais e meios de ensino. A Conferência também incluiu todo um tópico sobre a educação básica e profissional das pessoas privadas de liberdade. Fica a impressão de que, para contrapor-se à redação enxuta e compensar o último lugar atribuído à EJA do Documento de Referência, a plenária do Eixo VI optou por acolher toda sorte de propostas, sem estabelecer entre elas uma escala de prioridades, o que dificulta sua tradução em um número limitado de diretrizes e metas no novo PNE.
}

A própria Base Nacional Curricular Comum - BNCC aprovada em fevereiro de 2019, aliada a modelos de ranking educacionais por meio de avaliações externas, silencia a respeito do direito à especificidade da modalidade da EJA e, em sua organização, não considera as singularidades dos seus sujeitos. Pautada em discursos que desqualificam o serviço público, a BNCC fortalece iniciativas privadas que apresentam como solução para qualidade do ensino, pacotes pedagógicos prontos em detrimento de práticas curriculares da EJA que deveriam considerar "conhecimentos e capacidades que os fortaleçam como coletivo, que os tornem menos vulneráveis, nas relações de poder" (ARROYO, 2007, p.10).

Assim, embora a Educação de Jovens e Adultos seja defendida como uma estratégia para escolarizar, como nos diz Arroyo (2007, p.7), “(...) sujeitos concretos, em contextos concretos, com histórias concretas, com configurações concretas", contraditoriamente vivenciamos nos últimos anos o aprofundamento das desigualdades sociais, cenário em que pessoas que ficaram à margem da sociedade, que não puderam ou foram impedidos de concluir seus estudos, nos fazendo inferir que políticas generalistas não atendem às necessidades educacionais e a diversidade dos sujeitos da EJA.

$\mathrm{Na}$ esteira das disputas em que a educação de jovens e adultos é defendida como estratégia para escolarizar e ao mesmo tempo em que vivemos o fortalecimento de uma política neoliberal que tem agravado as desigualdades sociais pelas lógica generalista, o mundo é surpreendido pela pandemia Covid-19, as contradições entre o desafio de promoção do direito à educação, a defesa de emprego, da saúde e adoção de alternativas que reproduzem e ampliam as desigualdades sociais demonstrando as impossibilidades dessa saídas imediatista para educação de jovens e adultos na e para Amazônia bragantina. 


\section{A EDUCAÇÃO DE JOVENS E ADULTOS EM TEMPOS DE PANDEMIA DE COVID-19 NA AMAZÔNIA BRAGANTINA}

De modo espantoso e evidenciando a fragilidade humana para os chamados "seres invisíveis", o mundo inteiro foi tomado por um vírus, SARS-CoV-2 (do inglês Severe Acute Respiratory Syndrome Coronavirus 2) ou síndrome respiratória aguda grave do coronavírus 2, que iniciou em Dezembro de 2019 na China, na cidade de Wuhan, causando uma suposta pneumonia viral e rapidamente ganhou proporções gigantescas alcançando à todos e impondo novos modos de vida. A Organização Mundial da Saúde (OMS) passou a chamar oficialmente a doença causada pelo novo coronavírus de Covid-19. COVID significa COrona VIrus Disease (Doença do Coronavírus), enquanto "19" se refere ao ano de 2019 (FIOCRUZ, 2020).

O planeta parou para que o vírus parasse, mas milhares de pessoas no mundo não puderam parar e ficar em casa, porque milhares não tem casa e outros milhares não tiveram escolha: ou saiam de casa para trabalhar ou perdiam seus empregos evidenciando a desigualdade social existente no mundo e no Brasil, de modo geral.

No Brasil o vírus continua se alastrando e alcançou, a título de exemplo, no dia 24 de setembro de 2020, o número de 4.657.702 milhões de casos confirmados e 139.808 mil óbitos, com 831 óbitos nesse dia (BRASIL, 2020a). Quando esse artigo for lido por você certamente os números serão maiores.

Os impactos da pandemia são enormes, tanto a nível social, como econômico, político, cultural, histórico e educacional sem precedentes na história recente das epidemias. $\mathrm{Na}$ educação, a crise vivenciada pela Covid-19 resultou no encerramento das aulas em escolas e em universidades, afetando mais de 90\% dos estudantes do mundo (UNESCO, 2020).

Segundo a Unesco, se não forem criadas políticas públicas que invistam em melhorias na infraestrutura, tecnologias, formação, metodologias e salários, além do reforço da merenda, melhor aproveitamento do tempo, tutoria fora do horário usual das aulas e material adicional, os impactos serão sentidos por mais de uma década (UNESCO, 2020).

O Ministério da Educação (MEC) publicou a portaria no $^{\circ} 343$ de 17 de março de 2020, que orienta as Instituições de Ensino a substituírem as aulas presenciais por aulas em meios digitais pelo prazo de 30 dias ou pelo tempo que durar a pandemia (BRASIL, 2020b).

O parecer do Conselho Nacional de Educação - CNE do Ministério da Educação do Brasil reconheceu os problemas causados pela pandemia e procurou reorganizar as atividades acadêmicas com a permissão para aulas aos sábados - em horários de contraturno e durante as férias -, para que os alunos da Educação Básica não percam o ano letivo e apontou outras medidas semelhantes àquelas já defendidas pela Unesco (BRASIL, 2020c)

Todavia, e diante de toda essa situação mundial pandêmica, os alunos da EJA ficaram esquecidos. São alunos trabalhadores que precisam conciliar trabalho, estudo, família, filhos, e tantas outras responsabilidades e em meio a toda essa pandemia lutam por suas vidas e pela manutenção de seus empregos e sua condição de alunos que lhes é negada.

Assim como nas demais regiões do Brasil, na região Norte e na Amazônia bragantina também houve redução das turmas de EJA. No ano de 2005, em Bragança-PA, haviam 1.507 jovens e adultos matriculados, aumentando em 2012 para 2.642 matriculados e diminuindo, em 2017, para 1.388, ou seja, menos 1.254 matrículas, o que significa que em apenas cinco anos houve uma redução de 47,4\% de alunos na EJA (NEVES, SILVA JÚNIOR E GONÇALVES, 2019).

De acordo com os dados do Instituto Nacional de Pesquisas Educacionais Anísio Teixeira (INEP) houve uma queda de 7,7\% no número de alunos da EJA no Brasil, tanto no ensino fundamental quanto no ensino médio (INEP, 2019), isso representa 1.051.919 de matrículas a menos que no ano de 2010 , por exemplo. 
Corroboramos com Di Pierro e Ximenes (2011) ao afirmarem que não faz sentido as turmas estarem em redução no Brasil se os números de brasileiros com baixa escolaridade se mantém elevado, conforme segue,

\begin{abstract}
Como compreender que a oferta escolar esteja em declínio, se existe uma demanda potencial de mais de 60 milhões de brasileiros com idade igual ou superior a 14 anos que são analfabetos absolutos, pessoas com escolaridade reduzida ou que não concluíram o ensino fundamental? É possível imaginar que não exista demanda social por EJA se o mercado de trabalho requer níveis cada vez mais altos de escolaridade e qualificações profissionais? Por que os jovens e adultos não buscariam oportunidades de estudos se a participação na vida social, cultural e política é cada vez mais mediada por informação, conhecimento e tecnologia? (DI PIERRO E XIMENES, 2011, p.6).
\end{abstract}

A explicação para essa questão da redução na oferta de turma da EJA se pauta na escassez de recursos para essa modalidade de ensino e no pouco estímulo para continuidade da escolaridade em meio à rotina do jovem e adulto trabalhador que se sente exaurido pelo mundo do trabalho, sem ter condições de priorizar sua escolarização. Soma-se a isso o fato de que pela ausência de políticas públicas para incentivá-lo a estudar, por meio de auxílios ou bolsas de estudo, o aluno da EJA fica sem escolha ao fazer a opção entre trabalho e estudo.

Essa redução de oferta de turmas de EJA na Amazônia bragantina ocasionou, desde o ano de 2018, em uma nova forma de oferta: a nucleação, ou seja, só seriam ofertadas turmas em "escolas núcleo" da cidade, não mais em todas as escolas como antes.

O processo de nucleação se configura como uma oferta de turmas da EJA, cuja distribuição é realizada a partir de processos avaliativos como forma de controle de resultados, de modo que, pouca ou nenhuma evasão passa a ser o critério para manutenção da oferta ou fechamento de turmas em escolas do campo ou cidade, transformando algumas escolas como referência para a oferta da EJA, em bairros da área urbana ou em comunidades para os territórios do campo.

Para Messina (1993), há tempos as pesquisas demonstram que a demanda por EJA é modelada pela natureza e características da oferta educativa. Em São Paulo, por exemplo, desde 2011 já haviam estudos que apontavam a existência da política de nucleação na EJA, conforme afirmam Di Pierro e Ximenes (2011, p.10), "de fato, os dados e documentos reunidos evidenciam que, assumindo ou não as autoridades centrais, há uma política de nucleação e desestímulo em franca aplicação na rede estadual de ensino".

A lógica que permeia essa política é cruel e intencional, deseja o fim da educação pública e a não garantia de direitos aos jovens e adultos brasileiros, uma vez que, "diante do decréscimo de estudantes, reduz-se a oferta, o que, por sua vez, implica em crescente redução da demanda (DI PIERRO E XIMENES, 2011, p. 8).

Freire (1997) já destacava que a prática educativa para a EJA deveria ser pautada na realidade, na diversidade do aluno e nos conhecimentos construídos historicamente, para que a construção do saber fosse consolidada de maneira crítica, ou seja, assumir a realidade concreta para transformá-la.

Desse modo, em meio à toda essa precariedade na EJA na Amazônia bragantina as aulas são suspensas por conta da pandemia. A primeira proposta, e parece ser a única, que se considera em meio a essa situação vivida é a oferta de atividades de ensino por meio tecnológico, todavia a integração ao mundo tecnológico, midiático e informacional impõe-se como uma exigência quase universal, embora venha se realizando de forma desigual e até mesmo marginal, conforme as diferenças sociais, econômicas, políticas e culturais entre as regiões do planeta e do país, entre os grupos sociais e entre os indivíduos (SOARES E SANTOS, 2012). 
Se no Brasil os dados apontam que apenas 39\% dos domicílios brasileiros possuem computador (CETIC.BR, 2019), imaginem ter computador com acesso à internet na Amazônia bragantina quando as desigualdades sociais são extremas e cerca de $50 \%$ das pessoas vivem apenas com uma renda média mensal de até meio salário mínimo (DEEPASK, 2018).

Desse modo, a Educação a distância - EaD não pode ser a única solução, uma vez que esta metodologia tende a exacerbar as desigualdades já existentes, que são parcialmente niveladas nos ambientes escolares, simplesmente, porque nem todos possuem o equipamento necessário (SOUZA, FRANCO E COSTA, 2016). Registra-se ainda que há um grande movimento de luta nacional contra a oferta de aulas no modelo EaD para as turmas de EJA, aderir à essa concepção significa negar o direito à educação para todos com as mesmas condições de igualdade de acesso e permanência na escola.

A seguir apresentaremos algumas estratégias que podem se apresentar como alternativas para lidar com a situação da EJA em tempos de Pandemia de Covid-19 na Amazônia bragantina.

\section{REPENSANDO AS ESTRATÉGIAS DA EJA EM TEMPOS DE PANDEMIA: DESAFIOS E POSSIBILIDADES}

Diante desse contexto geral apontamos algumas provocações para repensar os caminhos da EJA no território da Amazônia bragantina em tempos da pandemia de Covid-19, no campo das estratégias e das possibilidades, no sentido de materializar uma política de EJA que potencialize a cidadania dos jovens e adultos neste território.

Todavia, é de fundamental importância que tenhamos conhecimento de um documento elaborado, em julho de 2020, pelos Fóruns de EJA do Brasil que tratam de ações necessárias para a EJA em tempos da pandemia de Covid-19. O documento aponta três pautas de luta, a saber:

1. O primeiro ponto da pauta de luta diz respeito a disponibilizar banda larga, como direito social, na forma de serviço público gratuito; plataforma pública, com expansão da Rede Nacional de Pesquisa (RNP); integração com TVs públicas, rádios públicas e redes sociais; e infraestrutura de tecnologia virtual, em sala de aula, como instrumentos de inserção no chamado ciberespaço com produção de transvídeos e construção de tipos textuais no celular, demonstrando as funcionalidades e aplicações na vida de cada educando(a) (FÓRUNS EJA BRASIL, 2020, p. 2). 2. O segundo ponto da pauta de luta é que reafirmamos que a oferta da EJA precisa tornar parte da constituição de políticas públicas de Estado (em âmbito federal, estadual, municipal e distrital) e não por meio de programas. Defendemos o direito à educação de qualidade e nos posicionamos contrários à oferta de atendimento compulsório da EJA na modalidade EaD. Exigimos que, para esse atendimento, o poder público e suas instituições (nos âmbitos federal, estadual, municipal e distrital) realizem o recenseamento, a mobilização da sociedade por meio de chamada pública e divulgação de vagas da demanda e garanta a abertura e manutenção de turmas/escolas de EJA na educação básica (Fundamental e Médio) na forma integrada à Educação Profissional nos termos do artigo 5o da LDB 9394/96 e Lei 13.005/2014 do Plano Nacional de Educação (Metas 9 e 10) (FÓRUNS EJA BRASIL, 2020, p. 3). 3.O terceiro ponto da pauta de luta é a defesa de que o ano letivo não precisa coincidir com o ano civil, principalmente, em situações excepcionais como a que nos encontramos. É possível organizar os dias letivos e horas, de modo a garantir o ensino presencial para todos(as), assegurando- se que: não haja discriminação devido às condições de vida dos(as) trabalhadores(as) estudantes e à estrutura das instituições educacionais; a autonomia aos sistemas (municipais, estaduais, federais e distrital) para definir suas formas de recuperação, com GESTÃO DEMOCRÁTICA, assegurando a participação das comunidades escolares, para propor e deliberar sobre as alternativas; a reorganização dos calendários escolares possibilitarão a reposição das aulas e atividades de modo presencial, assim que seja superada a pandemia da COVID-19, e as condições sanitárias permitam a viabilidade do retorno às escolas, 
garantindo a igualdade de condições .para todos(as), ainda que para isso se reconheça a necessidade de que as atividades do ano letivo de 2020, sejam estendidas até 2021 (FÓRUNS EJA BRASIL, 2020, p. 4).

Quanto ao primeiro ponto da pauta de luta, caso haja necessidade de opção pelo ensino remoto nas escolas, será vital que se garanta igualdade de condições para acesso e permanência às aulas aos alunos da EJA. A renda baixa dos alunos trabalhadores do munícipio de Bragança, na Amazônia bragantina, os impossibilita de fornecer a si próprios recursos tecnológicos e acesso à internet banda larga, por isso será necessário que a secretaria municipal de Educação, em parceria a outros órgãos governamentais, lhes dê as condições para tal. Em meio à pandemia sabemos que grande número de trabalhadores perderam seus empregos e, apesar do auxílio emergencial do governo federal que milhares de brasileiros receberam, ele se destina basicamente ao suprimento das necessidades básicas como alimentação e compras de remédios, além de que foi temporário e somente aos que não tinham nenhum vínculo empregatício.

Todavia, registra-se que essa oferta por meio do ensino remoto deve ser uma exceção pela situação vivida e que a Amazônia bragantina também deve se posicionar contrariamente à oferta compulsória da Educação a Distância às turmas de EJA, uma vez que se luta nacionalmente por uma educação de qualidade socialmente referenciada para todos.

No segundo ponto da pauta de luta exige-se políticas de EJA efetivas e não mais via programas governamentais, para garantir as condições necessárias de acesso, permanência e êxito à escolarização dos jovens, adultos e idosos, não somente neste contexto de pandemia, mas permanentemente. A EJA integrada à Educação Profissional e Tecnológica -EPT precisa se tornar política pública para garantir uma melhor qualificação aos alunos da educação básica, bem como a manutenção e a ampliação da oferta presencial nos três turnos como uma opção para os diferentes sujeitos que à acessam.

No terceiro ponto de pauta assegura-se a flexibilização do calendário do ano letivo vigente e que este não precisa coincidir com o ano civil, priorizando o aprendizado do aluno, seu processo formativo em detrimento de avaliações, aligeiramento, redução do calendário, bem como por questões meramente burocráticas da educação.

Esses três pontos pautam a compreensão da importância do diálogo coletivo para criar alternativas que tenham como foco os sujeitos da EJA e suas lutas pelo direito à educação e alternativas emancipatórias. Nesta perspectiva será necessário que se repense não apenas o conteúdo de ensino, mas o modo de ensinar e de aprender em seus tempos, sempre em diálogo com a diversidade dos alunos da EJA, aqui em especial destaca-se a Amazônia Bragantina.

Além das questões ponderadas e proposições acerca do contexto atual pandêmico para a EJA já descritas, provocamos outras reflexões sobre pontos que merecem visibilidade neste momento, tais como: a escola deve oportunizar aos jovens e adultos o protagonismo nos diferentes contextos de vida, assim como o trabalho deveria investir e incentivar no mesmo sentido, mas percebemos que há entraves nesta relação. Todavia, se o trabalho faz o jovem abandonar a escola, ele posteriormente o motiva à sua volta, porque compreende que a elevação da escolaridade melhora a qualificação profissional.

Faz-se necessário que a política de escolarização dialogue com os diferentes modos de trabalho e com os tipos de oferta para jovens e adultos no mundo do trabalho. A escola precisa estabelecer e fortalecer ainda mais os vínculos com os jovens, adultos e idosos e não deve travar as portas quando estes não voltarem ou perderem a motivação pelo estudo no decorrer deste período pandêmico e para além dele.

Por conseguinte, faz-se necessário observar os alunos que estão vivenciando o luto, que tiveram perda de referências e afetividades em suas vidas, que tem sofrido com queixas de ansiedade, insônia, depressão e ainda precisam trabalhar para fazer a manutenção da vida. Nesse sentido, a escola precisa se tornar cada vez mais um lugar de acolhimento das necessidades e interesses do aluno(a) da EJA, contribuindo diretamente na construção das suas histórias de 
vida. Na realidade da Amazônia Bragantina, como as aulas foram suspensas, houve como desdobramento o isolamento do contexto escolar que pode ser superado se a escola mantiver um vínculo comunicativo com os alunos, mesmo sem aulas.

O cenário atual que estamos vivendo é uma situação que vai mudar a sociedade, vai exigir da educação um novo design, currículos humanizados e mais interessantes, diálogos mais potentes, olhares mais afetuosos e sensíveis, discussão sobre a cultura escolar, que ainda impera, de expulsar o jovem da escola, e, fomentar a elaboração de outra cultura, do acolher e não excluir.

A secretaria de educação do município de Bragança-PA precisa fortalecer os esforços de qualificação dos gestores, professores, coordenadores pedagógicos e técnicos administrativos, para além de motivar, acolher, aprender como desenvolver competências socioemocionais no contexto da escola, realizar escutas mais ativas e fazer uso de novas ferramentas.

Para além dos pontos circunstanciados sobre a EJA em tempos de pandemia nos territórios da Amazônia bragantina, os impactos e traumas causados pela pandemia terão de ser considerados e explorados de um novo ponto de vista pedagógico. É um momento que as escolas possuem para repensar a sua função social na vida dos jovens e adultos, com expectativas, projetos e sonhos, como retrata muito bem no documentário "Nunca me Sonharam", 2017.

\section{CONSIDERAÇÕES FINAIS}

Este artigo se propôs analisar os direitos e as políticas para Educação de Jovens e Adultos em um município da Amazônia bragantina, frente ao contexto da pandemia de Covid19. Ao longo do texto tratamos questões referentes aos direitos, políticas educacionais, a EJA na Amazônia bragantina em tempos de pandemia e apresentamos proposições para a educação da EJA.

Todavia, compreende-se que os desafios das políticas educacionais sobre a permanência e êxito das pessoas jovens, adultas e idosas nos contextos escolares em tempos de pandemia precisam ser ainda mais efetivos e cuidadosos no sentido de garantir esse direito que ao longo da história foi negado e compensado com muitas fragilidades. Tal contexto, ainda pode ser mais excludente entre estes jovens se não considerar a relação com trabalho, pobreza, gravidez precoce, violência, problemas emocionais e o sentido da escola para eles.

A suspensão das atividades de ensino presenciais de forma regular, embora considerando parte dos estudantes tiveram acesso às atividades remotas, ocasionou uma ruptura na rotina de estudo de todos os estudantes brasileiros, entre eles, crianças, adolescentes, jovens, adultos e idosos de forma substancial, o que não representa e alcança a realidade educacional de onde estamos falando - Amazônia bragantina, que ainda não retornou as atividades de ensino presencial, assim como não conseguiram realizar atividades de ensino remotas a distância devido a dificuldade de acesso à internet e falta de recursos tecnológicos. Outro fator mais desafiante é alcançar os sujeitos da EJA em seus diferentes contextos de vidas, tais como: campo, ribeirinhos, agricultura familiar, territórios pesqueiros, coletores, dentre outros contextos sociais.

Assim sendo, em tempos de pandemia não deveria ser um momento de ataque aos direitos humanos conquistados e garantidos, de mais cortes na Educação e de eliminação de direitos trabalhistas, assim como a negação da valorização da modalidade de ensino de jovens e adultos e de outros conceitos e ideias que encontram-se alinhavadas à falta de equidade, qualidade e à amortização desta, mas de repensar as políticas de escolarização que dialoguem com os modos de trabalhos, de escolas que realmente tenham sentidos nos projetos de vidas das pessoas jovens e adultas. 


\section{REFERÊNCIAS}

ARROYO, Miguel. Balanço da EJA: o que mudou nos modos de vida dos jovens-adultos populares?. REVEJ@ - Revista de Educação de Jovens e adultos, v. 1, n. 0, p. 1-10, ago. 2007.

BRASIL. Constituição (1988). Constituição da República Federativa do Brasil. Brasília, DF: Senado Federal: Centro Gráfico, 1988. 292 p.

BRASIL. Lei $n^{\circ} 5692$ de 11 de agosto de 1971. Estabelece as diretrizes e bases da educação nacional. Diário Oficial da União, Brasília, DF, v. 1, p. 6.377, de 12/08/71.

BRASIL. Lei no. 9.394, de 20 de dezembro de 1996. Estabelece as diretrizes e bases da educação nacional. Diário Oficial da União, Brasília, DF, 23 dez. 1996.

BRASIL. Parecer CNE n. ${ }^{\circ}$ 11/2000. Ministério da Educação. Disponível em: http://confinteabrasilmais6.mec.gov.br/images/documentos/parecer_CNE_CEB_11_2000.pdf. Acesso em: 12 mar. de 2018.

BRASIL. MEC. Resolução No 3, de 15 de Junho de 2010. Diretrizes Operacionais para a Educação de Jovens e Adultos. CNE/CEB. Disponível em: www.forumeja.org.br. Acesso em: 19 de março 2018.

BRASIL. Lei n.13.005, de 25 de junho de 2014. Aprova o Plano Nacional de Educação PNE e dá outras providências. Diário Oficial da União, Brasília, DF. 26 jun. 2014.

BRASIL. CORONAVÍRUS BRASIL. Ministério da Saúde. Painel Coronavirus. 2020a Atualizado em 24/09/2020, às 18h30. Disponível em: https://covid.saude.gov.br/. Acesso em: 24 set. 2020.

BRASIL. Ministério da Educação. Portaria no 343 de 17 de Março de 2020. Dispõe sobre a substituição das aulas presenciais por aulas em meios digitais enquanto durar a situação de pandemia do Novo Coronavirus - Covid 19. 2020b. Disponível em:

https://epge.fgv.br/files/default/portaria-no-343-de-17-de-marco-de-2020.pdf. Acesso em: 24 set. de 2020

BRASIL. Conselho Nacional de Educação - CNE. Ministério da Educação. Parecer CNE/CP No 5/2020. Reorganização do Calendário Escolar e da possibilidade de cômputo de atividades não presenciais para fins de cumprimento da carga horária mínima anual, em razão da Pandemia da COVID-19. 2020c. Diário Oficial da União, Brasília, DF, 1 jun. 2020.

FIOCRUZ, Fundação Oswaldo Cruz. Por que a doença causada pelo novo vírus recebeu o nome de Covid-19? Disponível em: https://portal.fiocruz.br/pergunta/por-que-doencacausada-pelo-novo-virus-recebeu-o-nome-de-covid-19. Acesso em: 24 set. 2020.

CARVALHO, Maria Elizete Guimarães.; BARBOSA, Maria das Graças da Cruz; RODRIGUES, Susy Cristina de O.; TEIXEIRA, Luciana Martins. Contribuições da Educação em Direitos Humanos para as salas da EJA. In: I Congresso Internacional da Cátedra UNESCO de educação de jovens e adultos. João Pessoa: Editora Universitária da UFPB, 2010. v. 01. 
CETIC.BR. Centro Regional de Estudos para o Desenvolvimento da Sociedade da Informação. Pesquisa TIC Educação 2018(Cetic.br, 2018). Disponível em: https://cetic.br/media/analises/tic_educacao_2018_coletiva_de_imprensa.pdf. Acesso em: 12 jun. 2020.

DEEPASK. O mundo e as cidades através de gráficos e mapas. Ano 2018. Disponível em: http://www.deepask.com/goes?page=Renda-domiciliar:-Veja-a-renda-media-familiar-percapita-no-seu-municipio. Acesso em: 26 set. 2020.

DI PIERRO, Maria Clara; HADDAD, Sérgio. Transformações nas Políticas de Educação de Jovens e Adultos no Brasil no início do Terceiro Milênio: Uma Análise das Agendas Nacional e Internacional. Cad. Cedes, Campinas, v. 35, n. 96, p. 197-217, maio-ago., 2015.

DI PIERRO, Maria Clara. A Educação de Jovens e Adultos no Plano Nacional de Educação: Avaliação, Desafios e Perspectivas. Educ. Soc., Campinas, v. 31, n. 112, p. 939-959, jul.-set. 2010.

DI PIERRO, Maria Clara; XIMENES, Salomão Barros. Políticas e direitos educativos dos jovens e adultos no Estado de São Paulo: notas de Pesquisa e relato de intervenção. Conferência: $25^{\circ}$ Simpósio Brasileiro de Política e Administração da Educação (ANPAE). São Paulo, Janeiro de 2011.

FREIRE, Paulo. Pedagogia da autonomia: saberes necessários à prática educativa. 24. ed. São Paulo: Paz e Terra, 1997.

FÓRUNS EJA BRASIL. Mobilização Nacional dos Fóruns de EJA, Julho/2020. Disponível em: http://forumeja.org.br/sites/forumeja.org.br/files/Mobiliza\%C3\%A7\%C3\%A3o\%20Nacional \%20dos\%20F\%C3\%B3runs\%20de\%20EJA_0.pdf. Acesso em: 22 set. de 2020.

INEP, Instituto Nacional de Estudos e Pesquisas Educacionais Anísio Teixeira. Matrículas na educação de jovens e adultos caem; 3,3 milhões de estudantes na EJA em 2019. Disponível em: http://portal.inep.gov.br/artigo//asset_publisher/B4AQV9zFY7Bv/content/matriculas-na-educacao-de-jovens-e-adultos-cai3-3-milhoes-de-estudantes-na-eja-em-2019/21206. Acesso em: 21 set. de 2020.

LÜDKE, Menga; ANDRE, Marli E.D.A. A Pesquisa em educação: abordagens qualitativas. 2 ed. Rio de Janeiro: E.P.U., 2013

MACHADO, Maria Margarida. A educação de jovens e adultos no Brasil pós-Lei $\mathrm{n}^{\circ}$ 9.394/96: a possibilidade de constituir-se como política pública. Em Aberto, v. 22, n. 82, 2009.

MESSINA, Graciela. La educación básica de adultos: la otra educación. Santiago de Chile, Redalf/ Orealc, 1993.

NEVES, Joana d'Arc de Vasconcelos; SILVA JUNIOR, Sebastião Rodrigues da; GONÇALVES, Gabriela Oliveira. A Educação de Jovens e Adultos como direito fundamental: um olhar sobre o município de Bragança-PA. 3112 - Trabalho Completo - $2^{\mathrm{a}}$ 
Reunião Científica Regional Norte da ANPED (2018) GT 18 - Educação de Pessoas Jovens e Adultos. Rio Branco: Acre, 2019. ISSN:2595-7945

SAMPIERI, Roberto Hernández.; COLLADO, Carlos Fernández; LUCIO, Pilar Baptista. Metodologia de pesquisa. (Série Métodos de Pesquisa) 5. ed. Porto Alegre: AMGH, 2013

SOARES, Leôncio José Gomes. Educação de jovens e adultos. Rio de Janeiro: DP\&A, 2002.

SOUZA, Simone de.; FRANCO, Valdeni S.; COSTA, Maria Luisa F. Educação a distância na ótica discente. Educação e Pesquisa, São Paulo, v. 42, n. 1, p. 99-114, jan./mar. 2016

SOARES, Conceição; SANTOS, Edméa. Artefatos tecnoculturais nos processos pedagógicos: usos e implicações para os currículos. In: ALVES, Nilda. Libâneo, José Carlos. Temas de Pedagogia: diálogos entre didática e currículo. São Paulo: Editora Cortez, 2012. (p.308-330).

UNESCO. A Comissão Futuros da Educação da Unesco apela ao planejamento antecipado contra o aumento das desigualdades após a COVID-19. Paris: Unesco, 16 abr. 2020. Disponível em: https://pt.unesco.org/news/comissao-futuros-da-educacao-da-unescoapela-ao-planejamento-antecipado-o-aumento-das. Acesso em: 4 jun. 2020. 